operation to-day. The court of reference so long demanded has now materialized in the shape of the Food Standards Committee of the Ministry of Food.

\title{
REFERENCFS
}

Anonymous (1855). Quart. Rev. 96, $46 \mathrm{r}$.

Great Britain. Parliament ( 1856$)$. Third Report of the Select Committee of the House of Commons on the Adulteration of Food [C. 379]. London: H.M. Stationery Office.

Hassall, A. H. (1855). Food and its Adulterations. London: Longman, Brown, Green and Longmans.

\section{Recent Advances in Food Legislation for the Protection of the Consumer}

\section{By C. A. Adams, Food Standards and Labelling Division, Ministry of Food, London}

There is a growing consciousness the world over that the consumer needs protection to ensure that the food he buys is honestly portrayed so far as descriptions and claims made in advertisements and labels are concerned and that such food should not be adulterated. These are fundamental requirements, and provide the key to the food legislation of all enlightened countries. In the United States and Canada there are only two basic food offences, misbranding and adulteration, and the regulatory definitions of these are such that almost all offences against the food laws of these countries can be taken under the one or the other of these charges.

In this country the position is not so clear-cut, but $I$ think it can be shown that the advances that have been made since 1939 have taken us a long way along the road to our ultimate goal-the adequate protection of the consumer. The outbreak of the war prevented the Ministry of Health from exercising the potential power conferred by Section 8 of the new Food and Drugs Act, 1938. This power, somewhat reminiscent of the mantle of Elijah, was assumed by the Ministry of Food in 1943 in the form of Defence (Sale of Food) Regulations, but with several important differences.

The first is the definition of 'food'. Fitful amendments, not altogether successful, to the original definition have been made in successive Food and Drugs Acts since 1875 , but none succeeded in defining the position of the borderline products-hybrids that are partly food, partly medicine, and which could claim, according to circumstance, to be either. To some degree, the position has now been clarified by the addition of the proviso that an article shall not be deemed not to be a food merely because it is also capable of use as a medicine. Borderline preparations may be thus, with sound legal authority, classified as foods.

The second is the expansion of those time-honoured words 'nature, substance or quality', three facets of the indivisible whole featured in Food and Drugs Acts for three-quarters of a century, until they were separated in the 1938 Act. Even this separation, which enables charges under one or more of these heads to be preferred under Section 3 , is of no avail if false claims are made as to the nutritional or dietary value of a food, since it is by no means certain that a Court would hold that such claims were false as to the nature, or the substance, or the quality, of the food. Accordingly, 
Regulation 1 of the Defence (Sale of Food) Regulations speaks of false or misleading claims as to not only the nature, substance or quality, but also, and in particular, as to the nutritional or dietary value of a food. With this extension, misleading claims in respect of almost any attribute of a food, on labels or in advertisements, may now be challenged.

The third, the solution of the difficult case of a misleading title or claim, followed elsewhere on the label by a true statement of composition of the food, was attempted. On the basis of first impressions, it was considered that no subsequent addition eliminated the misleading impression created by the primary statement, and Regulation I (3), supporting and reinforcing the two previous sections, contains a novel and important principle, since it states that the fact that the label or advertisement includes an accurate statement of the composition of the food shall not preclude the Court from holding that the label or advertisement is misleading. The Regulations thus provide a powerful weapon in defence of the interests of the consumer, the more so since, during the war and subsequently, important propaganda has been based on the nutritional and dietary values of foods. This type of advertising has now become a national feature and it is as true to-day as when the 1934 Committee on the Composition of Food reported, that advertising is the real power in marketing. Although the law gives power to make regulations dealing with the labelling of food, no corresponding power exists as regards advertisements, with one exception-that relative to claims concerning the presence of vitamins and minerals, where precisely the same treatment is accorded to both labels and advertisements. Until this control is extended to all types of food advertisement, the control of labels will remain but a partial remedy.

\section{Labelling of foods}

The criticism frequently levelled at the foregoing legislation is of its essentially negative character, but the exercise of the power to make food regulations constitutes a positive approach, and the Ministry of Food, since 1943, has gone quietly ahead with the task of making positive legal provisions for the protection of the purchaser. Many will be familiar with the Labelling of Food Order, which lays down the information which must now, for the first time, be disclosed to the purchaser on the labels of prepacked foods. 'This information includes the packer's name and address, the common or usual name (if any) of the food, and a declaration of the ingredients from which the food is made. A statement of the minimum contents of the package is required by a recent Weights and Measures Order. Perhaps the most important provision of the Labelling Order, however, is that relating to vitamin and mineral claims, whereby any such claims, whether they appear on labels or in advertisements, have to be substantiated by a declaration on the label of the identity and quantity of the vitamin or mineral present. The manner in which this declaration has to be made is laid down in detail. Rules for the labelling of alcoholic liquors are also laid down, and, as a result, a purchaser is no longer in doubt as to the origin and, to some extent, to the quality of prepacked alcoholic beverages. The old chaotic position, under which inferior products had masqueraded as high-quality articles, no longer obtains. In consequence, the purchaser is now in a position to ascertain what he is purchasing by 
reading the label, and this happy position has been secured by the good work of the advisory service set up by the Ministry. This innovation is widely used, and to date well over 60,000 labels have been 'vetted'. As a result, by friendly and persuasive methods, the vast majority of food labels have been amended so that they are reasonably free from adverse comment-a result that could never have been achieved by the older methods of prosecution first and reform afterwards.

\section{Food standards}

Another major development in food legislation is that relating to food standards, but this is a movement not confined to this country by any means. Canada first entered the field of standards for food as long ago as 1890, the Food Adulteration Act, 1890, giving the Governor in Council authority to establish standards of quality for any food or drug. Increasing use of this power has convinced the Canadian authorities of the value of such standards, recently summarized so ably by Mr R. E. Curran, K.C., the legal adviser to the Department of National Health and Welfare at Ottawa (Curran, 195I): 'To-day, the purpose of a food standard is manifold. It is an assurance to the consumer that the food which he purchases is wholesome and nutritious. It is an assurance that it will not contain harmful substances nor substances which are substantially valueless to its composition. It is an assurance to the public that consideration has been given to the essential elements which a food should contain and it guarantees the presence of these elements. It is a specification to the manufacturer as to the factors which make up the worth of a food which in turn must be accepted as the criteria of its quality. These are amongst the factors which would ordinarily be considered as inherent in the purpose of a food standard.'

The attitude adopted by the United States was originally less forthright, and dependent upon the interpretation of what constitutes adulteration as set out in the Federal Food, Drug and Cosmetic Act of I 906 . As a guide to the enforcement of that part of the Act, the Food and Drugs Administration issued 'standards of identity' for various descriptions of foods, but these standards, not being authorized by the Act, had no legal sanction. The insecurity of this position at law was further demonstrated by the inability of the Food and Drugs Administration to satisfy the Court that an article of food, 'Bred-Spred'-a jam-like product with a low fruit content-was adulterated, since, though it did not conform to the standard for preserves, it was sold under a distinctive name to which the Court held the standard did not apply.

In 1935, President Roosevelt, in commending new food and drugs legislation, appealed to the Senate in these words: 'In such a situation as has grown up through our rising level of living and our multiplications of goods, consumers are prevented from choosing intelligently and producers are handicapped in any attempt to maintain higher standards. Only the scientific and disinterested activity of government can protect this honor of our producers and provide the possibility of discriminating choice to our consumers.'

Accordingly, the United States Food, Drug and Cosmetic Act of $193^{8}$ gave the Administrator power to prescribe standards of composition and identity for foods, so 
long as they are in the interest of the consumer, and the sanctity of standards has been invariably upheld by the United States Courts.

In this country, one or two 'standards' of sorts were included in our Food and Drugs Acts; butter, milk and cream are examples, but until the 1938 Act was passed, there was no power to make standards for foods by Regulation. The language of Section 8 , in which the Minister is given power to prescribe food standards so long as they are for preventing danger to health, loss of nutritional value or otherwise for the protection of the purchaser, is strongly reminiscent of both the Canadian and United States wordings; in effect it represents a synthesis of both. In all three instances, however, the power is delegated: in Canada to the Governor, in the United States to the Food and Drugs Administrator, and here to the Minister of Food; in no case are the standards laid down in the Acts.

In the formulation of standards, the same diversity of procedure is apparent. At one extreme lies the Canadian method, where the recommendations to the Governor come solely from officials, who, however, consult trade interests on any standard beforehand. At the other extreme, the United States method is based on public meetings having the characteristics of legal hearings, at which witnesses may be cross-examined, and of which a complete record is taken. The hearing completed, the evidence is considered by the Administrator, who, before proceeding to the making of a standard, is bound to publish the 'findings of fact', as derived from the hearing. What this means is best illustrated by the assertion in 1949 of a distinguished American lawyer, that their incomplete formal hearings on the proposed standards for bread had occupied 133 days, $26 \mathrm{I}$ witnesses testified to the tune of some $3,000,000$ words, and the transcript of evidence occupied 15,572 pages.

In this country, however, the procedure is a compromise of these extremes, we have a permanent Food Standards Committee, under the Chairmanship of the Minister's Scientific Adviser, whose members represent the Government Departments primarily concerned: the Ministry of Food, the Ministry of Health, the Department of Health for Scotland, and the Department of the Government Chemist, as well as technical and trade advisers. The Committee meets in private and examines proposals for food standards from all angles, including the fundamental one, whether a standard is necessary for the protection of the consumer. All who are likely to be affected by a standard may give evidence before the Committee. Usually, of course, this calls for the examination of trade witnesses, but in addition medical and enforcement representatives may give evidence. Ultimately the Committee reports its findings and recommendations to the Minister. If the recommendations are in favour of a standard, the report is published, so that all affected may have a further opportunity for comment. Finally, the recommendations, if accepted by the Minister, become the subject of a Food Standards Order.

As an example of yet another variant in the method of making food standards, South Africa might be mentioned. In that country, there exists a most energetic Bureau of Standards, whose energies spread well beyond the field of foods, constituted and financed something on the lines of our British Standards Institution. The Bureau, by delegating work to specialist committees, issues recommended food standards, and 
these are readily adopted by food manufacturers desirous of using the Bureau's mark on the label of their products. In this respect the system has much in common with our prewar National Marks scheme.

The prescription of a standard for even a single food calls for prolonged investigatory work and the exercise of judicial qualities of no mean order. It is our experience that even under the somewhat informal British procedure, it is straining optimism to expect the production of a standard in less than 12 months. Under the more formal procedure of the United States the time lag would be even greater, but for the fact that their standards hearings proceed more or less without interruption, a procedure not possible here with a Standing Committee. Standard making is not easy, and it is not speedy, but a standard affords effective protection to the consumer. The cost (borne by Local Authorities) of legal proceedings under Section 3 of our Food and Drugs Act coupled with the reluctance of magistrates to accept as 'standards' the views expressed by witnesses for the prosecution, deter Local Authorities from taking proceedings except in those cases where fact, e.g. conformity with a legal standard, and not opinion, is at issue. Thus, quite recently one Authority declined to risk the institution of proceedings under the Food and Drugs Act when a published code of practice, agreed between the Ministry and the 'Trade, had been grossly violated. In these circumstances, the only real protection for the consumer is the prescription of a legal standard, and the long hard path must therefore be followed.

If this be accepted, what ought to be the characteristics of a standard of food composition? Should it, for example, deal with the complete composition of the food, and should its numerical details be fixed or should they provide ranges of variation? Or would it suffice if the chief or essential ingredients of a food were controlled within limits, leaving the manufacturer free to vary other constituents at will?

At the moment, British standards merely prescribe minimum standards to which some characteristic ingredient or ingredients must conform, e.g. $85 \%$ spices in curry powder, without specifying the individual spices. This is certainly the simplest type of standard, but obviously one not always free from criticism. A more stringent control is the characteristic of American standards, which aim at covering the total composition of the food. To a certain extent variety is catered for by the standard including permissive ingredients in addition to obligatory ones, but to us this process savours more of standardization. If the manufacturer's product contains an ingredient not covered by these categories, his food may be held to contravene the standard, and the trader's only remedy is to persuade the Administration to amend the standard.

An important question is whether sales of substandard products should be permitted, if the labelling conveys this information. In this country it is no offence to manufacture a substandard food-the offence is selling, and selling under a description which suggests to the purchaser that he is getting a food for which a standard has been prescribed. If the description is remote from that of the standard food, ought the sale to be an offence? I must confess that we have no final views on this problem yet. In North America efforts are being made by the Food and Drugs Administration to establish that the sale of a substandard food is illegal under any label. To refer to the 'Bred-Spred' case I mentioned earlier, it must be acknowledged that it looks like jam, 
it will be eaten like jam, and may be supplied as a substitute for jam. Would not, then, the case for the Preserves standard be undermined if a cheapened imitation, however speciously it is labelled, were on the market? At the moment, the American Supreme Court is wrestling with this proposition. Many of our own Food and Drugs Authorities have questioned similar cases, without risking the institution of proceedings to test their views.

\section{Enforcement of food regulations}

In "enforcement matters there are also some differences in the three countries. The Dominion of Canada is covered by five district organizations, each under a technical official, centralized in the Department of Health at Ottawa, but one and the same law is operative throughout. In the United States, the Federal Law operates only in respect of food in interstate traffic, and for these goods sixteen districts, each with its own laboratory but maintaining close contact with Washington headquarters, operate. In this country, the enforcement of our law for the protection of the consumer is a duty laid by the Food and Drugs Act upon local Food and Drugs Authorities, which are independent and number over 200 , and although they are advised by highly qualified Public Analysts, there is clearly room for all shades of opinion on any suggested offence, which militates against the adoption of any single line of action throughout the country.

\section{Contamination of foods}

Let us now' return to the activites of our own Food Standards Committee, apart from the consideration of subjects for Food Standards Orders. 'The addition of substances, whether voluntary or involuntary, to food is increasing, and it is only necessary to mention the use of chemicals which may have harmful effects, or the addition of preservatives and colouring matters, by way of illustration. Subcommittees of the Food Standards Committee have now been formed, the first dealing with the omnipresent metallic contamination of foods. Already a report on arsenic has been published, and others will follow in due course on lead, copper, zinc and other metals. The second subcommittee is more recent and will consider, under the chairmanship of Professor Dodds, what changes are necessary in the present list of preservatives and other adulterants in food in Food Regulations to bring them abreast of modern knowledge and ideas.

\section{Conclusion}

It may fairly be said that energy and initiative are being shown in seeing that advantage is taken of the latest scientific knowledge in recommending food regulations for the protection of the purchaser. On this, my final comment will be a very general one, but in some measure it concerns each one of us. If the consumer is to be protected adequately, it is vitally necessary for all interested, both in food production and in the knowledge of the part good food should play in our economy, to work in season and out for complete honesty and integrity in the marketing of food. In my opinion, members of an important society such as this, have a momentous part to play in working towards the establishment of a firmly developed public opinion on these matters. Enlightened food and drugs law is of the greatest significance to the whole country, and the 
knowledge of this fact is growing. True, we have not got to the stage in this country where food and drugs law has as high a priority in the legislature as it undoubtedly has in North America. But those of us who have worked in this field have reason to be thankful for the change of heart that has come about in the last few years, and in the increased interest of both trade and public. It was in order to further this interest that I accepted the Chairman's invitation to speak here this morning, and I only hope I have made a few more converts to a worthy cause.

REFERENCE

Curran, R. E. (195I). Food Drug Cosmetic Law Y. 6, 204.

\section{Problems in the Administration of the Laws Relating to the Food of Men and Animals}

By J. King, Government Laboratory, Clement's Inn Passage, London, W.C. 2

The laws relating to the sale of food for man and for animals differ in certain important respects. With human food, the consumer is the main party to be protected, but with animal food, both the farmer and his livestock must have their interests protected. The Food and Drugs Act, 1938 , together with the various Statutory Instruments, protect the human consumer mainly by the application of Section 3, which makes it an offence to sell to the prejudice of the purchaser anything that is not of the substance, nature and quality demanded. This Act differs from the Act of 1928 in empowering the appropriate Minister to make suitable standards which are from time to time embodied in Statutory Instruments. This newer legislation is dealt with by Adams (1951) and will not be amplified here. To a smaller extent the Merchandise Marks Act, 1926, is a protection, particularly in transactions within the food trade.

\section{Fertilisers and Feeding Stuffs Act, 1926}

The Fertilisers and Feeding Stuffs Act of 1926 differs from the above acts in being far more specific. The sale of animal feeding-stuffs must, for example, generally be accompanied by a Statutory Statement, the particulars required varying with the type of article, and being enumerated in five Schedules incorporated in the Act. In addition to the Statutory Statement, the vendor may make a voluntary statement relating to certain ingredients not scheduled in the Act, e.g. he may declare that dried grass contains over $100 \mathrm{mg}$. carotene/1000 $\mathrm{g}$. This voluntary statement is binding under the Act and may also make the vendor liable to action under the Merchandise Marks Act. Regulations embodied in the Act specify limits of error that are allowed to cover small differences due to imperfect mixing and differences in analyses, for although the Regulations include methods of analysis, some variation is inevitable, due to slight differences in technique. Methods and scales for sampling are also included in these Regulations.

The two forms of legislation are similar in that they require that sampling shall be done by duly appointed inspectors, and in a particular manner. Also that the analysis 